Karolina Werner-Lewandowska

Politechnika Poznańska

E-mail: karolina.werner@put.poznan.pl

\title{
LOGISTICS MATURITY OF 3 PL SERVICE PROVIDERS - EMPIRICAL RESEARCH RESULTS
}

\begin{abstract}
Background: The chapter is devoted to the logistics maturity of enterprises providing transport and storage services. Production, trade and service enterprises, regardless of the industry or company's size, strive to improve their operation in order to gain competitiveness on the market and to increase profits. Maturity models allow to assess the current situation of the organization and to determine the direction of further development [Kosieradzka \& Smagowicz, 2016, s. 280-293]. Over the years, depending on the management areas, many different maturity models have been emerged [Looy, 2014, s.5-10; Steenberg et al., 2010, 317-332; Janse et al., 2010; Eadie et al., 2011; Battista et al., 2012; Bemelmans et al., 2013; Cao and Jiang, 2013; Battista and Schiraldi, 2013; Jellouli and Abdel-kadhi, 2013; Mazur and Stachowiak, 2014; van Lith et al., 2015; Benmoussa et al., 2015; Tontini et al., 2016]. Additinally, some logistic maturity models that analyze logistics processes occurring in enterprises have been developed [Battista et al., 2012]. In the chapter, the author propose a maturity model dedicated to the service sector, in which the areas of logistic activity are subject of evaluation, not logistic processes. It results from the fact that service enterprises, unlike production companies, rarely have precisely defined processes of logistics suport as they concern on the service's delivery process.

Methods: In the research the original logistics maturity model for the service sector (LMM4SI) was used. The assessment of the maturity level is made on the basis of an interview using a questionnaire containing questions on the company's use of 65 logistic engineering tools. The set of chosen tools was created based on the list of the 100 most popular logistics tools proposed by G. Richards, S. Grinsted [Richard \& Grinsted, 2016], which were verified regarding applicability in service industry and own proposals were added.
\end{abstract}


Tools are assigned to 5 areas of logistics activity. The proposed model includes 6 levels of maturity, which are determined by the impact of the logistics tools.

Results: 190 Polish enterprises providing services in the field of transport and storage were included into the research. The surveyed group of enterprises is dominated by areas of logistic activity related to transport management. However $89 \%$ of enterprises use means of transport to provide a service, the dominant level of logistics maturity achieved by service companies in the area of transport management is L1. Moreover $99 \%$ of all surveyed companies have their own fleet. Only for $13 \%$ of the surveyed enterprises it was possible to assess the area related to Supply and Inventory Management. In this area, the vast majority of companies achieved the logistics maturity level L1. In the remaining enterprises, no supplies of materials necessary to perform services in the future were collected.

Conclusions: The research objective of the chapter is to determine the relationship between the size of a service enterprise and the achieved logistics maturity level. The presented research results indicate to what extend companies providing logistic services have achieved internal logistics maturity. On this basis, it is possible to determine whether the size of the enterprise affect the level of logistics maturity.

Keywords: logistics maturity, logistics service providers, transport, storage

\section{INTRODUCTION}

According to Central Statistic Office (GUS) data, in 2018 in the Polish service sector, enterprises belonging to the transport and storage industry accounted for $12 \%$ of enterprises [GUS, 2019]. In addition, logistics service providors generate the largest GDP impact among Polish service enterprises [GUS 2019].

Following the report "Logistics in Poland. Report 2017", developed by ILIM $^{1}$,,revenues from sales of transport and warehouse services have been growing since 2008 [Feschner and Szyszka 2018]. This resulted in an improvement in the overall business climate indicator of the transport and warehouse management section as assessed by the GUS [Feschner and Szyszka 2018]. According to the ILIM report, enterprises in this section also face the same development obstacles including a lack of availability of qualified employees and increasing employment costs. The increase in demand for transport and warehouse services with the

${ }^{1}$ ILIM - Instytut Logistyki i Magazynowania, ang. The Institute of Logistics and Warehousing 
associated problems with qualified employees, it all cause a deterioration in the logistics indicators examined by ILIM, describing the customer logistics service level [Feschner and Szyszka 2018]. Owing to that, in this chapter special attention was paid to the on-time delivery index, which has been falling since 2013. The root causes for the above problem are: (i) an insufficient level of cooperation between production and distribution companies and logistics operators, and (ii) undertaking cooperation with external transport companies only in the seasonally increasing demand for transport services and warehouse management services.

In this research, author is going to verify whether enterprises from the transport and warehouse management section, in terms of logistics maturity, can contribute to the increase of logistic indicators at their business partners in the supply chain.

\section{RESEARCH OBJECT}

In the research, 2000 Polish service enterprises were included representing 11 service sections according to the Polish code list of classification of business. To keep the aspect ratio of research objects representing particular service sections, in the research the author examined approximately 200 enterprises from each service section. As part of the study, 190 companies providing transport and storage services were examined. The structure of the companies population according to the company's size, measured by the employment level, is presented in Fig. 1, where E stands for the employment / employees level.

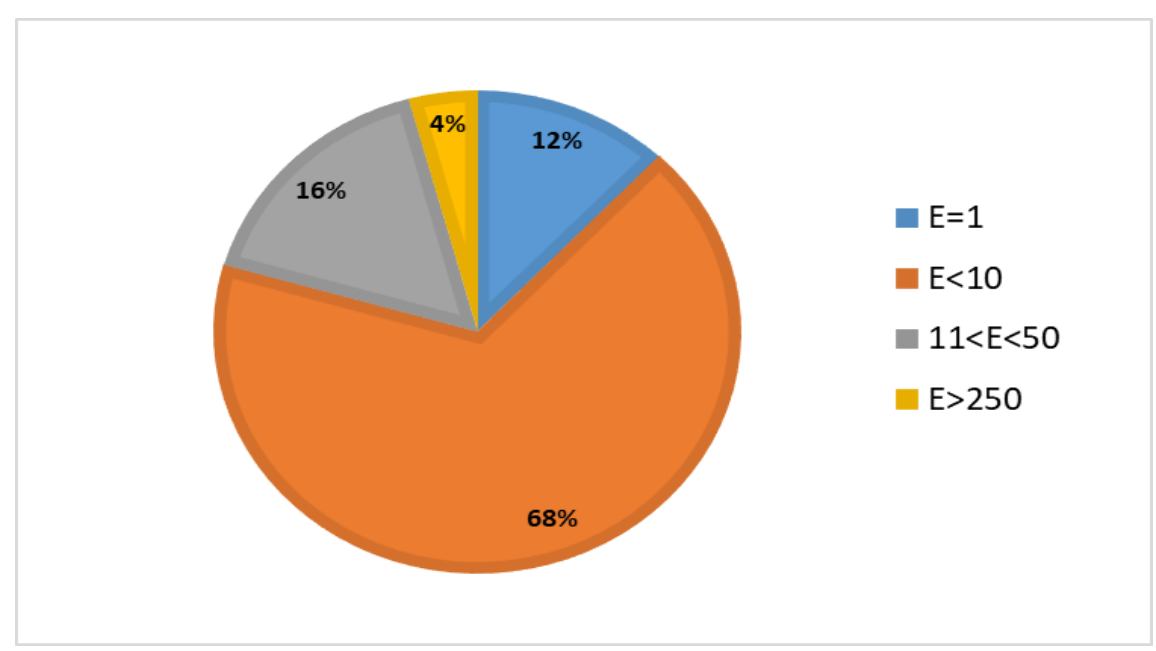

Fig. 1. The structure of the studied population of enterprises by company's size. Source: own work

With reference to Fig.1, it was noticed that the major group of companies under study are micro enterprises employing less than 10 people $(E<10)$, however one-man business $(E=1)$ 
was given off this group, treating it as a separate category. Owing to the fact, that none of medium sized companies (50-250 Employees) agree to the participation in the survey research, they were not included into research. It should be noticed, that the structure of the studied population coincides with the structure of employment in the transport and warehouse management section. When in transport and storage services since 2016 the share of selfemployed people reached $9.5 \%$, in construction it was $15.9 \%$, and in trade it was $10.03 \%$ [Feschner and Szyszka 2018].

\section{RESEARCH SUBJECT AND METHODOLOGY}

The subject of the presented research was the logistics maturity of service enterprises. In the research the logistics maturity dedicated to the service sector was used. The detailed description of this model may be found in: [Werner-Lewandowska and Kosacka-Olejnik 2018; Werner-Lewandowska and Kosacka-Olejnik 2019a; Werner-Lewandowska and Kosacka-Olejnik, 2019b].

The model is based on the assumption that the level of logistics maturity is determined by the logistics engineering tools used by the service enterprise [Werner-Lewandowska and Kosacka-Olejnik, 2019b]. As a consequence, it was stated that the logistics engineering tools set which is used by logistics companies is a research subject. The tools used in the research have been assigned to 5 areas of logistics activity of service enterprises: warehousing (WM), transport (TM), inventory and supply (SIM), supply chain management (SCM), IT support (IT), which allow to assess the logistics maturity of the company considering 6 levels of evaluation (L1-L6). In the model, the the L0 level was included, which indicates that in a particular assessment area, more than $50 \%$ of logistics tools are not known in the enterprise. It is noteworthy, that some logistics areas including: warehouse (WM), transport (TM) and inventory \& supply (SIM) may be not evaluated, if they are excluded from the study (NA) based on the answer for the filtering questions, presented in the Table 1.

Table 1. Filtering questions used in the research

\begin{tabular}{|c|c|c|c|}
\hline $\begin{array}{c}\text { Question } \\
\text { ID }\end{array}$ & Logistics area & Major issue & Description \\
\hline F1 & WM & Storage place & Is there any place for storing materials needed to provide services in the future? \\
\hline F2 & TM & Means of transport use & Is the means of transport used for the service? \\
\hline F3 & TM & Own vehicle fleet & Does the company have its own vehicle fleet? \\
\hline F4 & SIM & Materials collection & Does the company collect materials needed to provide services in the future? \\
\hline
\end{tabular}

Source: own work. 
Filtering questions concerned those areas of logistics activity that may not occur in a service enterprise, due to organizational conditions, the scope of provided services, or the scope of application of the outsourcing strategy. In areas such as supply chain management (SCM) and IT support (IT), it has been assumed in the research that each of these activities is associated with every business activity and each time it can be assessed. Consequently, each enterprise is a partner in the supply chain and uses IT solutions.

It was assumed that, if a company do not use more than $50 \%$ of logistics engineering tools in a given logistics area under assessment, so this area can not be a subject of evaluation (NE). The overall research results showing the achieved levels of maturity of particular groups of companies in percentage, are presented in Table 2.

Table 2. Maturity levels of transport and warehouse services providers depending on the employment rate (the percentage of

\begin{tabular}{|c|c|c|c|c|c|c|c|c|c|c|c|c|c|c|c|c|c|c|c|c|}
\hline \multirow{2}{*}{ Level } & \multicolumn{4}{|c|}{ WM } & \multicolumn{4}{|c|}{$\mathrm{TM}$} & \multicolumn{4}{|c|}{ SIM } & \multicolumn{4}{|c|}{$\mathrm{SCM}$} & \multicolumn{4}{|c|}{ IT } \\
\hline & 1 & $<10$ & $11-49$ & $>250$ & 1 & $<10$ & $11-49$ & $>250$ & 1 & $<10$ & $11-49$ & $>250$ & 1 & $<10$ & $11-49$ & $>250$ & 1 & $<10$ & $11-49$ & $>250$ \\
\hline L0 & 0 & 0 & 0 & 0 & 48 & 23 & 48 & 13 & 0 & 0 & 6 & 0 & 43 & 55 & 52 & 50 & 0 & 5 & 0 & 0 \\
\hline L1 & 0 & 8 & 16 & 25 & 13 & 8 & 3 & 75 & 0 & 2 & 10 & 38 & 22 & 21 & 35 & 38 & 0 & 0 & 0 & 0 \\
\hline L2 & 0 & 15 & 16 & 25 & 13 & 16 & 6 & 13 & 0 & 0 & 0 & 0 & 9 & 6 & 6 & 13 & 0 & 15 & 16 & 25 \\
\hline L3 & 9 & 5 & 32 & 13 & 0 & 4 & 0 & 0 & 0 & 0 & 0 & 0 & 0 & 0 & 0 & 0 & 4 & 0 & 0 & 0 \\
\hline $\mathrm{L} 4$ & 4 & 2 & 0 & 0 & 0 & 3 & 13 & 0 & 0 & 1 & 3 & 0 & 13 & 13 & 0 & 0 & 4 & 10 & 16 & 75 \\
\hline L5 & 0 & 0 & 0 & 0 & 9 & 27 & 0 & 0 & 0 & 2 & 6 & 13 & 0 & 0 & 6 & 0 & 74 & 63 & 61 & 0 \\
\hline L6 & 0 & 5 & 35 & 38 & 0 & 8 & 10 & 0 & 0 & 0 & 0 & 0 & 0 & 0 & 0 & 0 & 13 & 7 & 6 & 0 \\
\hline
\end{tabular}

\section{LOGISTICS MATURITY OF ONE-MAN BUSINESS COMPANIES - RESEARCH RESULTS}

In the Warehouse Management area (WM), 87\% of the surveyed enterprises were not analyzed, as they have not had any space for storing materials required to perform services in the future. The remaining $13 \%$ of the surveyed enterprises have reached the logistics maturity level L3 and L4 in the WM area. According to the model, the L3 level means that the company reaches the level of logistics management, integrating management functions and treating logistics as a company's management strategy.

The L4 logistics maturty level means that enterprises move into the supply chain phase as they perceive added value of working with other companies. Failure to achieve higher levels of maturity (L5, L6) by one-man business results from the ignorance of such logistics tools as:

- Warehouse space calculation (not known by $100 \%$ of all respondents),

- Warehouse location (not known by $67 \%$ of all respondents), 
- Warehouse audit (not known by $67 \%$ of all respondents),

- Warehouse location numbering (not known by $67 \%$ of all respondents),

- Innovetiveness of warehouse (not known by $67 \%$ of all respondents).

The use of the following tools, including: Selecting warehouse storage equipment and tool: How to ,green” the warehouse and save anergy and CSR?; which were a prerequisite to achieve logistics maturity level L3 or L4 by one-man business among which $67 \%$ have used these tools. It is intereseting, that at the same time all one-man business companies have declared lack of inventory. Owing to that, the area of Supply and Inventory Management, (SIM) was not analyzed in the research. In author's opinion, the above may be a result of lack of building up stocks intentionally, so the indicated storage space is used to store materials that have not been used to provide the current service, but may be used in the future. Consequently, the inventory is a result of buying a larger quantity forced by unit packaging or a logistic minimum specified by the suppliers e.g. in the transport and storage industry, it is a buble wrap for for packing and securing shipments. Lack of inventory for future services may results from the fact that self-employment is characteristic for transport companies that are providers of services for logistics companies [Feschner \& Szyszka (ed.), 2018] and their service does not require stock collection.

In the Transport Management (TM) area, only 4\% of enterprises were excluded from the further analysis, as they have indicated that they do not use means of transport to provide services. $13 \%$ of the surveyed enterprises were not assessed because they have used less than $50 \%$ of the tools ascribed to this area. In the rest of companies, $48 \%$ of them have reached the L0 level, because more than $50 \%$ of transport management tools were unknown. The least known tools were: Selection of transport management system (TSM) and Transport audit checklist (related to infrastructure), which were unknown by $57 \%$ of enterprises. It is noteworthy, that $9 \%$ of one-man business companies have achieved high logistics maturity level - L5, characterized as Network and Globalization.

With reference to the SCM area, $43 \%$ of one-man business enterprises have reached L0 in this conext. This is due to the ignorance of such tools as (they were unknown for $67 \%$ of companies):

- Supply chain risk assessment,

- Time- based process mapping,

- Omni-channel distribution,

- Strategic procurement, 
- Supply chain management audit,

- CPFR.

Regarding IT support area, one-man business enterprises in $74 \%$ of cases, have reached logistics maturity level - L5, and 13\% the highest level - L6. These companies are not familiar with such tools as: EDI, RFID, NFC, Z-WAWE, on average in $75 \%$ of cases. However, most of them $(74 \%)$ do not use such tools as: ERP, Truck \& Tracing and Cloud.

\section{LOGISTICS MATURITY OF MICRO COMPANIES - RESEARCH RESULTS}

In the Warehouse Management area (WM), 65\% of the surveyed enterprises were not analyzed, as they have not had any space for storing materials required to perform services in the future. The remaining $35 \%$ of the surveyed enterprises have reached the following logistics maturity levels (it refers to companies assessed in this logistics area): L1 - 8\%, L2$45 \%, \mathrm{~L} 3-5 \%, \mathrm{~L} 4-2 \%, \mathrm{~L} 6-5 \%$. In the WM area the companies under study declare lack of use of the following tools (in average $51 \%$ of enterprises): $5 \mathrm{~S}$ or $5 \mathrm{C}$ and Using warehouse management system (WMS). Moreover, in the companies under study into this research, 73\% of them do not use the Warehouse audit, while a $67 \%$ do not assess a warehouse regarding its innovativeness.

In the area of Supply and Inventory Management, 95\% of micro-enterprises surveyed into the research, have declared lack of inventory of materials for providing services in the future. The remaining group of companies $(5 \%)$ has reached the logistic maturity level L4 or L5. Each of logistic tool related to this area is known an average by $90 \%$ of enterprises, however there are some unused tools such as Square root rule (unused by $83 \%$ of companies). In author's opinion it is not a negative phenomenon, but it is rather justified, because service companies do not need to maintain a dispersed stock.

In the area of the Transport Management, $10 \%$ of enterprises were excluded from the further analysis, as they have indicated that they do not use means of transport to provide services. Only $2 \%$ of the surveyed enterprises were not assessed because they have used less than $50 \%$ of the tools ascribed to this area. In the remaining cases, $23 \%$ of enterprises have reached the L0 logistics maturity level, because more than 50\% of transport management tools were unknown, level L1 was achieved by $8 \%$ of the surveyed enterprises, L2 - 16\%, L34\%, L5 - 27\%, L6 - 8\%. Micro enterprises primarily have not known such tools as: Selecting a transport management system (TMS) - 62\%, and Transport audit checklist - in 77\% of cases. However, as much as $62 \%$ of the surveyed micro-enterprises do not use the calculation of the 
demand for transport services taking into account the size of cargo and transport capacity. In author's opinion it may results from high competition among micro enterprises providing transport services that try to carry out each order without calculating the order's parameters.

Regarding the SCM area, 55\% enterprises employing up to 10 employees have achieved Logistics maturity level L0. It is a consequence of the ignorance of such tools as: Supply chain risk assessment, Time-based process mapping, Omni-channel distribution, Strategic procurement, Supply chain management audit and CPFR. On average, 73\% of surveyed enterprises have indicated that they have not known these tools.

With reference to the area of IT suport, $63 \%$ of micro enterprises have achieved L5 logistics maturity level, while $7 \%$ of them have been fully mature in this area (L6). On the other hand, $5 \%$ of companies have known less than $50 \%$ of logistics tools into this research area. The most often unknown tools were NFC, Z-WAWE, pointed by around $88 \%$ of companies.

\section{LOGISTICS MATURITY OF SMALL COMPANIES - RESEARCH RESULTS}

In the Warehouse Management area (WM), all surveyed enterprises have declared that they have some space for storing materials required to perform services in the future. The results of the logistics matrity levels achieved by small companies were as following: L1 -16\%, L2 - 16\%, L3 - 32\%, L6 - 35\%. The small companies know all logistics tools defined in this logistics area, however, 68\% of them have not used Warehouse Space Calculation, e.g. calculation of the number of transhipment docks. Considering the fact that, the object of research were companies providing transport and warehouse management services, lack of use of this tool should be treated as a negative phenomenon, difficult to explain, in author's opinion.

With reference to the Supply and Inventory Management area, 74\% of small enterprises under study have declared lack of inventory of materials for providing services in the future. The remaining companies have reached the following logistic maturity levels: L0-6\%, L1 - 10\%, L4 - 3\%, L5 - 6\%. It should be noticed, that small enterprises use or know the various logistics tools however, the knowledge and use level may be diversified among companies. For instance, $63 \%$ of the surveyed enterprises do not know the tool Consignment stock, and $63 \%$ of them do not use the tool: Measurement of demand variation, which is important, in particular in the case of transport services, as the demand for this service is seasonal. 
In the area of Transport Management, $19 \%$ of $10 \%$ of enterprises were excluded from the further analysis, as they have indicated that they do not use means of transport to provide services. In the remaining cases, $48 \%$ of enterprises have reached the L0 logistics maturity level, because more than $50 \%$ of transport management tools were unknown, level L1 was achieved by $3 \%$ of the surveyed enterprises, L2 - 6\%, L3 - 4\%, L4 - 13\%, L6 - 10\%. Small enterprises primarily have not known such tools as: Selecting a transport management system (TMS) - 64\% of companies, and Transport audit checklist- in $64 \%$ of cases. In author's opinion, this phenomena should be considered as negative, in particular because these companies have own vehicle fleet. What is more, $52 \%$ of these companies do not use the calculation of the demand for transport services taking into account the size of cargo and transport capacity, what is also relevant in this case.

Regarding the SCM area, small enterprises have reached L0 logistics maturity level in $52 \%$ cases. It results from ignorance of such tools as: Supply chain risk assessment, Timebased process mapping, Omni-channel distribution, Strategic procurement, Supply chain management audit and CPFR. An average, $60 \%$ of all surveyed enterprises indicated lack of knowledge of these tools.

With reference to the area of IT suport, $6 \%$ of small enterprises have achieved the highest maturity level - L6, while the vast majority of companies (61\%) have achieved L5, and $16 \%$ of them have represented L4 or L2 maturity level. Small companies have not known primarily such tools as: EDI, RFID, NFC, Z-WAWE (on average in $71 \%$ of cases). Moreover, $71 \%$ of small enterprises have not used the Truck \& Tracing Shipment Tracking System, although $84 \%$ of them make Online Purchases, what in author's opinion is unusual result.

\section{LOGISTICS MATURITY OF LARGE COMPANIES - RESEARCH RESULTS}

In the area of Warehouse Management, all surveyed large enterprises have declared having some space for storing materials needed to perform services in the future. In this area, companies under stude have avhieved follwing logistics logistic maturity levels: L1 - 25\%, L2 - 25\%, L3 - 13\%, and L6 - 38\%. It was noticed that, large companies know all logistics engineering tools used into this research. Owing to the fact that $63 \%$ of companies do not use Warehouse space calculation, e.g. calculation of the number of transhipment docks, it was perceived as a negative phenomenon in enterprises providing services in the field of transport and storage. 
With reference to the Supply and Inventory Management area, 50\% of large enterprises have declared lack of inventory of materials for providing services in the future. In the remaining cases, these enterprises reached the following levels of logistics maturity: L1-38\%, L5 - 12\%. Large enterprises have known 12 of 18 tools assessed in the SIM area. 50\% of them have not known the following tools: Consignment Stock and Vendor Managed Inventory (VMI) or Co-Managed Inventory (CMI). Large enterprises have not used primarily use such tools as: Square root rule (75\%), Reorder point inventory management system (50\%) and Consignment Stock (50\%).

In the area of Transport Management, all large enterprises have been analyzed into research, which proves their use of means of transport to perform services, and the use of a minimum of $50 \%$ of the tools determining logistic maturity in this area. Large enterprises achieved the following logistics maturity levels, respectively: L0 - 13\%, L1 - 75\%, and L2 - 13\%. It is noteworthy, that relatively low levels of logistics maturity in the area of transport achieved by large enterprises result from the fact that these companies do not use the tool: Calculating the demand for transport services taking into account the size of cargo and transport capacity. In author's opinion it should be seen as a negative phenomenon in this industry, and difficult to explain in particular because large enterprises belong to international corporations.

Regarding the SCM area, $50 \%$ of large enterprises have achieved L0 in terms of logistics maturity. It results from ignorance of knowing such tools as: Time-based Process mapping, Omni-channel distribution, Strategic procurement, Supply chain management audit and CPFR. It is noteworthy, that on average, $50 \%$ of the surveyed enterprises have not known these tools. In author's opinion it is a negative phenomenon for large enterprises.

In the area of IT support, large enterprises have achieved L2 or L4 logistics maturity level, in $25 \%$ and $75 \%$ of cases, respectively. Large comapnies have not been familiar with $25 \%$ of tools used in the logistics maturity assessment into this area. It should be noticed that $63 \%$ of enterprises have not known the NFC tool, and $75 \%$ of them have not used Bluetooth technology, while none of companies have used Virtual Cloud. In author's opinio nit may be a consequence of using other technologies, that were not included into survey.

\section{CONCLUSIVE REMARKS}

To sum up the presented research results, there were made some conclusions on the results of logistics maturity levels achieved by companies considering the company's size (Table 2): 
C1: In the area of Warehouse Management, emplyment rate does not affect the knowledge of logistics tools, as no enterprise has achieved level L0. However, there is a noticeable proportional relationship between the size of a company and the maturity level. The maturity level increase (L6) with increasing size of the company.

C2: In the area of Transport Management, there is no clear relationship between the maturity level and the company size. For the author is was a surprising result, as it contradicts the popular opinion that large enterprises providing transport or warehouse services are better organized in terms of logistics processes, and thus they provide higher quality services.

C3: With reference to the Supply and Inventory Management area, it is noteworthy, that stock holding is determined by the size of the enterprise in terms of the employment rate. What is more, there is also a correlation with the logistics maturity level, so the bigger company is, the higher maturity level it achieves, but not exceeding the level L5.

C4: In the area of SCM, it can be generally stated that the employment level affects the level of knowledge about logistics tools related to this area. Cosequently, the larger the enterprise, the fewer number of unknown tools. However, it is difficult to notice the correlation between the size of the enterprise and the logistics maturity level.

C5: In the IT support area, results are quite different than expected by the author as the company is smaller, the logistics maturity level is higher.

To sum up this issue, it was stated that there is no clear correlation between the employment level and the logistics maturity level of service enterprises in the transport and warehouse management section.

Further conclusions will be related to unknown logistics engineering tools in particular areas of logistics activity, according to the subject of research. Owing to the fact that, companies under study were only asked about the use of a given tool (excluding analysis of causes of lack of use of a tool), so in author's opinion it would be difficut to submit the results to scientific discussion.

C6: In the area of Warehouse management, the lack of knowledge about logistics tools applies primarily to micro enterprises. When the company's size increases, the ignorance level decreases.

C7: In the area of Supply and inventory management, there is no noticeable correlation between the level of employment and lack of knowledge about logistics tools.

C8: In the area of Transport Management, lack of knowledge about logistics tools such as Selecting a Transport Management System (TSM) (64\% of respondents), and Transport 
Audit checklist, applies only to micro and small enterprises. It is noteworthy, that the tool: Calculating the demand for transport services taking into account the size of cargo and transport capacity, according to this research, is used only by one-man business. In author's opinion, no use of this tool by micro, small and large enterprises may be the reason for the decrease in the value of the on-time delivery indicator (see: Introduction).

C9: In the SCM area, regardless of the company's size, the same logistics tools are unknown. In author's opinion, in particular ignorance of CPFR is very negative as these companies provide services to other business entities and as logistics operators they should cooperate in planning, inventory forecasting and replenishment with partners in the supply chain.

C10: In the IT suport area, such an IT solution as NFC, Z-WAWE are not known to most enterprises, regardless of their size. Lack of knowledge about EDI and RFID dominates in one-man business and small enterprises.

In conclusion, considering the research objective, it was stated that the size of the company may affect achieved logistics maturity level, however it relates to some logistics activity area, not all of them.

The list of logistics tools unknown to enterprises providing transport and warehouse services is a value-added of conducted research as elimination of this ignorance may be a recommendation for enterprises to increase logistics maturity level. Consequently, the quality of provided logistics services should be higher and their market position should be better.

As a direction of further research, the author proposes to develop a roadmap for service enterprises, which will aim to show the way to achieve higher levels of logistics maturity.

The presented research is based on the use of the original model of logistics maturity dedicated to the service sector (LM4SI), which results in limitations for the described research such as: a list of 65 logistics tools, assigned to 5 areas of logicality of a service enterprise, adopting a 50\% threshold as a determinant of assessment logistics maturity, or recognition of logistics maturity at the L0 level. Improvements or modifications of the proposed model may constitute a direction for further research.

\section{ACKNOWLEDGEMENTS}

This chapter refers to the research financed by the National Since Center, Poland, project “Research on logistics maturity in service enterprises”, grant no. 2016/21/D/HS4/02116. 


\section{REFERENCES}

Battista C, Fumi A., Schiraldi M., 2012, The logistic maturity model: guidelines for logistic processes continuous improvement, POMS 23rd Annual Conference. Chicago, Illinois, USA.

Ballou R.H., 2007, The evolution and future of logistics and supply chain management. European business review, 19(4), 332-348. DOI: 10.1108/09555340710760152

Bemelmans, J., Voordijk, H., and Vos, B., 2013, Designing a tool for an effective assessment of purchasing maturity in construction. Benchmarking: An International Journal, 20,342361. DOI: $10.1108 / 14635771311318126$

Benmoussa, R., Abdelkabir, C., Abd, A., and Hassou, M., 2015, Capability/maturity based model for logistics processes assessment: Application to distribution processes. International Journal of Productivity and Performance Management,64, 28-51

Cao, W., and Jiang, P., 2013, Modelling on service capability maturity and resource configuration for public warehouse product service systems. International Journal of Production Research, 51, 1898-1921. DOI: 10.1080/00207543.2012.720391

Eadie, R., Perera, S., and Heaney, G., 2011, Key process area mapping in the production of an e-capability maturity model for UK construction organisations. Journal of Financial Management of Property and Construction, 16,197-210.

Feshner I., Szyszka G. (red.), 2018, Logistyka w Polsce. Raport 2017, ILIM, Poznań.

Kosieradzka A., Smagowicz J., 2016, Analiza porównawcza modeli dojrzałości organizacji [w:] M. Ćwiklicki, S. Jabłoński, S. Mazur (red.), Współczesne koncepcje zarządzania publicznego. Wyzwania modernizacyjne sektora publicznego, Fundacja Gospodarki i Administracji Publicznej, Kraków, 280-293.

Janse, B., Schuur, P., and de Brito, M. P., 2010, A reverse logistics diagnostic tool: the case of the consumer electronics industry. The International Journal of Advanced Manufacturing Technology, 47, 495-513. DOI: 10.1007/s00170-009-2333-Z

Jellouli, O., and Abdelkadhi, M.,2013, Test Logistics Maturity of the Industrial Zone in the Region of Gabes. International Journal of Supply Chain Management, 2, 71-75.

Lahti, M., Shamsuzzoha, A. H. M., and Helo, P., 2009, Developing a maturity model for Supply Chain Management. International Journal of Logistics Systems and Management,5, 654-678. DOI: 10.1504/IJLSM.2009.024796

Mazur, A., and Stachowiak, A., 2014, The framework of methodology for identification of organizational maturity with assessment of excellence level of logistics systems. In The 
Management between profit and social responsibility, Proceedings of the 4th Review of Management and Economic Engineering International Management Conference, edited by I. Abrudan, 18-20

Richards G., Grinsted S., 2016, The Logistics and Supply Chain Toolkit. Over 100 Tools for Transport. Warehousing and Inventory Management 2nd ed., USA: Kogan Page Limited, v-viii.

Steenbergen M., Bos R., Brinkkemper S., Weerd I., Bekkers W., 2010, The Design of Focus Area Maturity Models, „Global Perspectives on Design Science Research”, z. nr 6105, 317-332.

Tontini, G., de Carvalho, L. C., Schlindwein, N. F. D. C., and Tomarevski, V. ,2016, Maturity model of procurement and supply management in small and medium-size enterprises: A benchmarking of hospitals and metal-mechanic companies.International Journal of Quality and Service Sciences, 8, 315-333.

van Lith, J., Voordijk, H., Matos Castano, J., and Vos, B., 2015, Assessing maturity development of purchasing management in construction. Benchmarking: An International Journal, 22, 1033-1057

van Looy A., 2014, Business Process Maturity: A Comperative Study on a Sample of Business Process Maturity Model, Springer-Verlag, Berlin, 5-10.

Werner-Lewandowska, K. Kosacka-Olejnik, M., 2018, Logistics maturity model for service company - theoretical background. Procedia Manufacturing, 17, 791-802, DOI: 10.1016/j.promfg.2018.10.130

Werner-Lewandowska, K., \& Kosacka-Olejnik, M., 2019a, Logistics Maturity Model for Engineering Management - Method Proposal, Management Systems in Production Engineering, 27(1), 33-39, DOI: 10.1515/mspe-2019-0006

Werner-Lewandowska K., Kosacka-Olejnik M., 2019b, Logistics engineering application in the logistic maturity model for the service enterprises, Proceeding of The 14th International Conference of Logistics and SCM System, Chinese Martime Institute, 229-236.

Główny Urząd Statystyczny (GUS), 2019, Rachunki kwartalne PKB 2014-2018. Warszawa, Główny Urząd Statystyczny, Available on the Internet: http://stat.gov.pl (01/10/2019). 